\section{Morino \\ F. Bellomo \\ P. Milano \\ L. Bertignone \\ M. Sabra}

\title{
Reinforcement rings in acetabular revisions: our trends
}

Received: 8 September 2001

Accepted: 4 November 2001

\begin{abstract}
The authors, reviewing the international literature with their clinical experience developed in reconstructive surgery of acetabular defects due to aseptic loosening of acetabular cups, suggest their guidelines to the right use of acetabular reinforcement rings.
\end{abstract}

L. Morino $(\varangle) \cdot$ F. Bellomo $・$ P. Milano

L. Bertignone $\cdot$ M. Sabra

First Department of Orthopaedics,

C.T.O. Orthopaedic Hospital

Via Zuretti 29, I-10126 Turin, Italy

Tel.: +39-011-693-35-73

Fax: +39-011-693-37-60

E-mail: paolomilano@libero.it
Key words Reinforcement acetabular rings $\cdot$ Revision total hip arthroplasty

\section{Introduction}

The increasingly widespread use of hip arthroplasty (800 000 operations annually worldwide) has involved a consequent and evident increase in complications related to hip replacement, among which aseptic loosening is the main cause of long-term failure [1].

Many authors, assessing the normal cup biomechanics and in particular its elasticity, believe that implanting a rigid acetabular cup seriously damages the acetabular kinematics [2]. In fact, the joint surfaces, the subchondral bone and the periacetabular trabecular systems are related in such a way to have a correct transmission of the high stresses produced by the standing position and by gait. Consequently, the mechanical failure of a prosthetic cup is due to the coupling between the host bone that works with an elasticity module greater than that of the prosthesis, a structure that is rigid, and the cup itself. If we also consider the immunologic factors, the features of the materials in use and the local tissue reaction, it is evident that the loosening of a prosthetic cup is quite a likely event and, consequently, it has to be thoroughly monitored over time.

The aseptic loosening of a prosthetic cup often causes an acetabular deficit that may be treated by taking into account the amount and quality of the residual intact bone. The main factors causing such acetabular deficits are the following [3]: 
Table 1 GIR (Italian Group for Revision Surgery) classification of acetabular bone-loss

$\begin{array}{ll}\text { Type } 1 & \text { Acetabular loosening and/or enlargement-deformation with wall preservation } \\
\text { Type } 2 & \text { Acetabular enlargement-deformation with loss of one wall } \\
\text { Type } 3 & \text { Acetabular enlargement-deformation with loss of two or more acetabular walls and/or of the acetabular fundus } \\
\text { Type } 4 & \text { Massive-total acetabular bone loss }\end{array}$

- The amount of bone defect existing before the primary implant

- The over-reaming of the prior implant

- The wear of the loosened cup induced by debridement and by impingement with the acetabulum

- The accidental bone destruction during the removal of the prosthetic cup

The acetabular defects are defined by accurate classifications. Currently, the most widely used are the following:

- American Academy of Orthopaedic Surgeons (AAOS) [4]

- Paprosky [5]

- Italian Group for Revision Surgery (GIR) (Table 1) [6, 7]

These classifications have diagnostic and therapeutic purposes. However, in acetabular revisions often the surgeon's responsibility is not only to comply with strict protocols, but also to be flexible and resourceful to overcome the various problems that may occur.

In our opinion, the basic guidelines for acetabular revisions are as follows:

- To remove loosened components while preserving the residual intact bone as much as possible [8]

- To restore the acetabular integrity and continuity through the use of bone grafts (restoration of the bone-stock) and possibly by means of reinforcement rings

- To restore the correct centre of rotation

- To search for a complete primary stability of re-implanted components [9]

- To minimise the dysmetria existing between the lower limbs [10]

The basic requirement to properly achieve these goals is an accurate clinical planning before surgery supported by imaging diagnostics (e.g. radiography, scintigraphy, echo color Doppler, angiography). The revision techniques may vary according to the different anatomical situations resulting from the removal of the loosened prosthetic cup. From the review of the literature the current trends are the following:

- Acetabular deficits according to GIR I/II. According to the different cases, it is possible to use primary implant cups, whether associated or not with bone grafts, by possibly cementing the cup or stabilising it with pelvic screws.

- Acetabular deficits according to GIR II/III. In these cases, the following may be used:

- Large hemispherical cups

- Ovoid cups
- Metal reinforcement rings such as Müller, BurchSchneider, Ganz, associated with bone grafts and Polyethylene (PTE) cemented cups

- Acetabular deficits according to GIR IV, Paprosky III and AAOS IV/V. The following may be used:

- Metal reinforcement rings such as Burch-Schneider, Octopus associated with bone grafts and PTE cemented cups

- McMinn stemmed cup with anchoring stem in the ilium

- Saddle prosthesis

The use of fixed implants with large amounts of Polymethyl methacrylate (PMMA), in order to fill in bone defects, is a temporary solution and long-term results are not satisfactory.

\section{Reinforcement rings}

The international literature [11-18] fully agrees on the use of metal reinforcement rings to treat severe acetabular defects. The surgical technique adopted is also quite standardised. Currently, the rings mostly used are the following: - Müller ring [11-13] has been distributed on the international market since 1978. It is made of pure titanium and is available in sizes with $36-58 \mathrm{~mm}$ internal diameters.

- Ganz hooked reinforcement ring [14] has been distributed on the international market since 1987. It is made of pure titanium and is available in sizes with $36-64 \mathrm{~mm}$ internal diameters.

- Burch-Schneider reinforcement scaffold [15, 16] has been on the market since 1976. It is made of pure titanium and is available in $44-50 \mathrm{~mm}$ sizes, with right and left versions due to its design.

- The Octopus system for pelvic anchoring [17, 18].

These reinforcement rings have to be fixed to the residual intact bone in a mechanically stable manner by means of titanium screws and their anchoring systems (the lower flange of Burch-Schneider ring has to be fixed into the ilium, while the Ganz ring hook anchors itself in the obturator foramen). This creates a system able to increase the pelvis bearing surface, protecting the fragmented and compressed bone grafts to fill in the acetabular deficit and allow- 


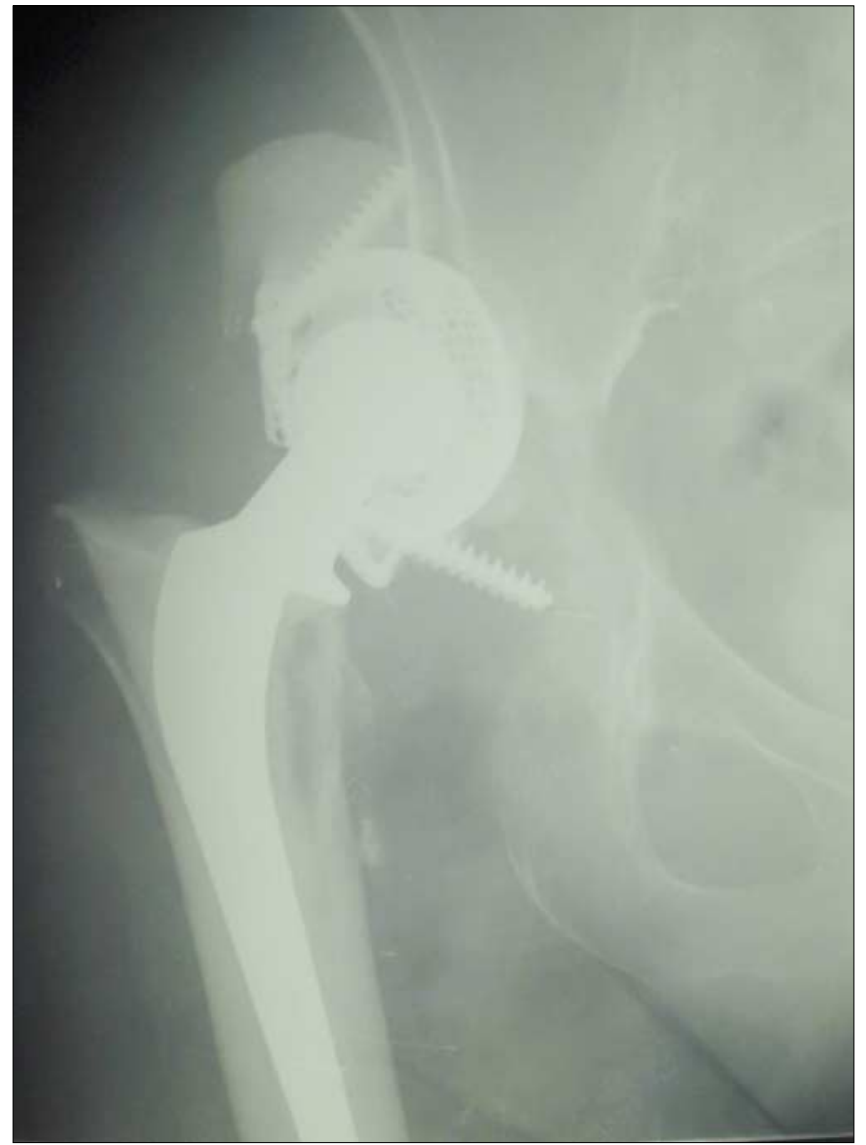

Fig. 1 Aseptic loosening of cementless cup with supra-acetabular graft

ing to cement a polyethylene (PE) cup inside them. On the basis of our experience, we recommend using inside the ring a PE cup of the following size: for the Müller ring a size smaller than the ring size, for the Ganz ring a smaller or equal size, for the Burch-Schneider scaffold a greater or equal size. It is possible to freely orient the PE cup in the space in order to restore the correct joint relations. This is partly unrelated to the orientation of the ring that, however, has to be anchored to the residual intact bone. This makes the system extremely versatile, and able to compensate for some defects related to the position of the unloosened femoral stem in situ (Figs. 1, 2).

\section{Discussion}

Our philosophy with regard to hip revision surgery has been to use the prosthetic system that seemed most suitable to solve the type of loosening and bone loss encountered. This enables us to adopt the most adequate solution

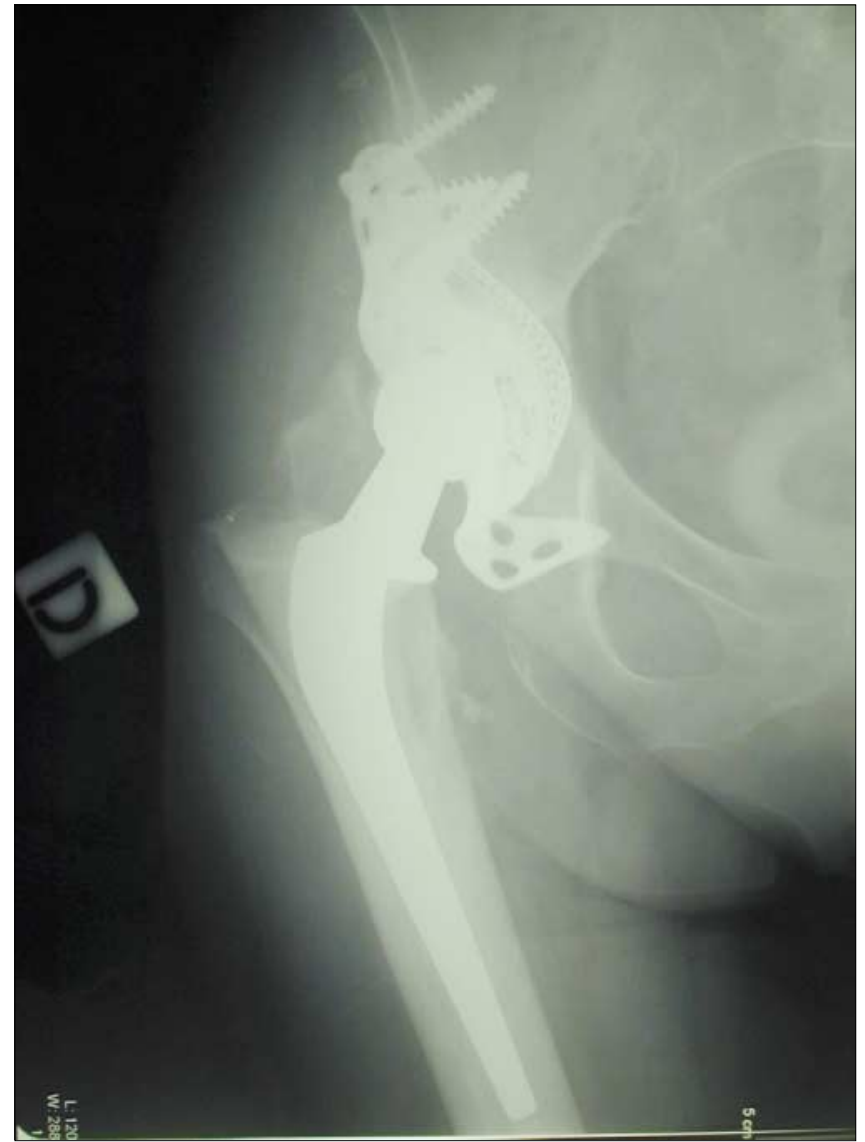

Fig. 2 Aseptic loosening after acetabular reimplantation using the reinforcement ring (3 years follow-up)

for each case. A drawback has been that our learning curve about the individual systems has been slow. Although the patients we have treated are not homogeneous, we can confirm that acetabular reinforcement rings are a valid method to treat severe acetabular deficits.

The greater is the acetabular deficit, the higher is the number of the difficulties generally encountered to make a revision (anaesthesiological and resuscitation techniques). Therefore it is necessary to monitor the prosthetic implants over time, in order to promptly detect the early signs of loosening and estimate the best time to intervene, to avoid dealing with a severe acetabular defect resulting from a "wait and see" attitude.

Our experience in the field of acetabular revisions makes us emphasise the need for the surgeons dealing with such disease to have a well organised bone bank, allowing to easily make use of autologous or homologous bone grafts duly treated and preserved. We prefer to use grafts with chips, rather than massive bone grafts, as the latter tend to resorb, even after many years, in particular if they cover more than $30 \%$ of the area of the cup, with a bearing function. 
In conclusion, only an accurate knowledge of the available methods, combined with the assessment of the patient's general and local conditions, may allow the surgeon to choose a suitable treatment for the disease of the replaced hip. It is necessary that surgeons dealing with such disease share their views and experiences on an ongoing basis, providing data and experiences that will lead to the development of standardised guidelines.

\section{References}

1. Cozzolino F, Loffredo A (1996) I fallimenti delle protesi d'anca; revisione della letteratura e proposta di classificazione. GIOT 22(1):24-32

2. Massin P, Roycamille R (1993) Les deformations du cotyle en charge avant et apres l'implantation prothetique. Rev Chir Orthop 70:89-98

3. Mauro PP, Musselli M, Scagnelli R, Trossarello P, Massè G (1996) Gli anelli di sostegno con l'uso di cemento acrilico nei reimpianti acetabolari. GIOT 22[Suppl 1](2):591-596

4. D'Antonio J (1988) Classification and management of acetabular abnormalities in total hip replacement. Clin Orthop Rel Res 243:126-137

5. Paprosky WG, Lawrence J, Cameron HU (1990) Acetabular defect classification: clinical application. Orthop Rev 14 [Suppl]:3

6. Pipino F, Molfetta L, Capozzi M (1994) The tecnique of reimplantation as it related to bone defect. Chir Org Mov 79:295-303

7. Pipino F, Molfetta L (1992) I reimpianti protesici d'anca nell'artrite reumatoide. GIOT 12:34-37
8. Balderston RA, Rothman R (1993) The hip. Verduci, Roma, cap 27, p 451

9. Mc Dermott AG, Langer F, Pritzker KP, Gross AE (1985) Fresh small-fragment osteocondral allografts; long term follow-up study on first 100 cases. Clin Orthop Rel Res 197:96-102

10. Garbuz D, Morsi E, Gross AE (1996) Revision of the acetabular component of a total hip arthroplasty with a massive structural allograft; study with a minimum five-year follow-up. J Bone Joint Surg Am 78(5):693-697

11. Starker M, Kandziora F, Jager A, Kerschbaumer F (1998) Acetabular reconstruction using acetabular reinforcement rings. Orthopade 27(6):366374

12. Korovessis P, Stamatakis M, Baikoulosis A, Katonis P, Petsinis G (1999) Mueller roof reinforcement rings. Medium-term results. Clin Orthop Rel Res 362:125-137

13. Haentjens P, Handelberg F, Casteleyn PP, Opdecam P (1986) The Muller acetabular support ring. A preliminary review of indications and clinical results. Int Orthop 10(4):223-230
14. Panski A, Tauber C (1997) Acetabular supporting ring in total hip replacement. Arch Ortop Trauma Surg 116:233-235

15. Gill TJ, Sledge JB, Muller ME (1998) The Burch-Schneider anti-protrusio cage in revision total hip arthroplasty: indications, principles and long-term results. J Bone Joint Surg Br 80(6):946-953

16. Schatzker J, Glynn MK, Ritter D (1984) A preliminary review of the Muller acetabular and Burch-Schneider anti-protrusio support rings. Arch Ortop Trauma Surg 103(1):5-12

17. Marinoni EC, Fontana A, Castellano S, Denti M (1994) The Octopus system for acetabular reconstruction. Chir Org Mov 79(4):357-360

18. Randelli G, Marinoni EC, Visentin C (1996) Il cotile Octopus. GIOT 22 [Suppl 1] (2):609-613 